\title{
Comparison of Displacement Measurements and Simulation on Fillet Weld of Steel Column Base
}

\author{
Nobuhiro Shimoi ${ }^{1, ~}$, Carlos Cuadra ${ }^{1}$, Hirokazu Madokoro ${ }^{1}$, Kazuhisa Nakasho ${ }^{2}$ \\ ${ }^{1}$ Department of Machine Intelligence and Systems Engineering, Akita Prefectural University, Yurihonjo, Japan \\ ${ }^{2}$ Department of Information Science and Engineering, Yamaguchi University, Ube, Japan
}

\section{Email address:}

shimoi@akita-pu.ac.jp (N. Shimoi), carlos@akita-pu.ac.jp (C. Cuadra), madokoro@akita-pu.ac.jp (M. Madokoro), nakasho@yamaguchi-u.ac.jp (N. Nakasho)

${ }^{*}$ Corresponding author

\section{To cite this article:}

Nobuhiro Shimoi, Carlos Cuadra, Hirokazu Madokoro, Kazuhisa Nakasho. Comparison of Displacement Measurements and Simulation on Fillet Weld of Steel Column Base. International Journal of Mechanical Engineering and Applications. Special Issue: Advanced Vibration-Based Structural Health Monitoring Methods for Civil and Mechanical Systems. Vol. 8, No. 5, 2020, pp. 111-117. doi: 10.11648/j.ijmea.20200805.11

Received: August 25, 2020; Accepted: September 23, 2020; Published: October 20, 2020

\begin{abstract}
The Hyogoken Nanbu earthquake (Kobe earthquake) that occurred on January 17. 1995, caused extensive and severe damages to a large number of buildings in Kobe city area. After the earthquake many steel structures were constructed using frame welded joint of welded construction and welded base. However, the capacity of these weld joints to absorb energy during earthquakes is small. For that reason, it is believed that in the design of steel structures that use welded joints, strong earthquake resistant characteristics must be provided in special for those joints of the steel welded bases. Moreover, these weld joints have little capacity to absorb energy during earthquakes. Therefore, for designing steel structures incorporating welded joints, strong earthquake-resistance characteristics must be specially provided for those joints of steel welded bases. Furthermore, structural monitoring will be necessary. Using simple dynamic measurements and simulations, this report evaluates the resistance and displacement characteristics of fillet welded construction by piezoelectric joint sensors.
\end{abstract}

Keywords: Anchor Bolt, Deformed Bar, Health Monitoring, Piezo Electric Limit Sensor, Steel Weld Joint

\section{Introduction}

Japan's social capital stock was accumulated and concentrated during its era of high economic growth. Its future deterioration is a mounting concern. Over the next 20 years, facilities 50 years old or older will become increasingly common. Therefore, the urgent need exists to maintain and renew such aging infrastructure. Unfortunately many steel structures were constructed using frame-welded joints of fillet welded construction and a welded base [1] Many steel-framed buildings in Japan use welding or bolting as a joining method. For bolt fastening, when a dynamic external force such as an impact, vibration or thermal load (expansion) affects the bolted joint, the bolt often loses its fastening force because of nut loosening. By contrast, few accidents occur with welded joints [2].

However, because of heat effects during welding, brittleness develops around the joint as it hardens. In fact, a relation exists between heat treatment of quenching and annealing of the steel material [3]. Therefore, achieving structural soundness might be difficult. Even if one strives to analyze the results of measurements at the initial stage of joining and the results of aging over 10 years using finite element method (FEM), one cannot assess crack growth or perform defect location realistically. The problem is regarded as extremely difficult.

In Japan, which has experienced the extremely powerful Great East Japan Earthquake, architectural design standards are necessary to prevent buildings from collapsing when absorbing seismic energy capable of plasticizing an entire building when a huge earthquake with seismic intensity of 6 or greater occurs. However, at present, no report describes monitoring of structural integrity by long-term precise measurements concentrated only on the joint part [4]. This is true also for other economically developed countries that have experienced strong earthquakes. For this study, we 
constructed a monitoring system able to measure structural soundness "easily," "inexpensively," and "over a long-term" through autonomous damage inspection of welded joints of steel structures, and by using sensor output. We investigated the design and measurement technology of a piezoelectric joint sensor that enables displacement prediction [5].

\section{Destructive Testing of Fillet Welds}

\subsection{Comparison with Conventional Technology}

Various methods are used as measurement technologies for quantitative evaluation of soundness for disaster prevention and reduction of structures. Assuming a sensor system used for displacement and vibration measurements with static loading, displacement is measured using a laser displacement meter or a contact displacement meter; natural vibrations are always measured using a fine vibration meter. A method exists of identifying the location of fracture and stress concentration using FEM analysis [6, 7]. Moreover, $\mathrm{X}$-ray analysis using FEM is useful for nondestructively and quantitatively evaluating the residual stress of structures. Nevertheless, it is difficult to analyze crack growth using this method. Among these methods, for microwave tremor measurement, the natural period of the structure is obtained using the Fourier spectrum ratio of the vertical component and the horizontal component. The amplification characteristics and natural period are obtained by finding the $\mathrm{H} / \mathrm{V}$ spectrum ratio and by normalizing the horizontal vibration to vertical vibration. The measurement system comprises a microwave tremor generator, a data logger, and a PC. It costs about 1.5-2.5 million yen per measurement unit. In the method using a laser Doppler velocity meter (LDV), the laser light is irradiated onto the measurement target. The speed is detected from the phase difference between the irradiation light and the reflected light because of the Doppler effects. This measuring system consists of two LDV devices, a data logger, a PC, and a digital displacement meter. The cost per measuring unit is about 45-60 million yen. The X-ray non-destructive device can be installed for monitoring limited places, but it is not practical for long-term measurement because it requires a power source. Also, the equipment cost is about $8-10$ million yen. Long-term monitoring of more than 20 years is necessary to achieve safety and soundness of joints of structures. However, no measurement device currently guarantees the required monitoring period or a method or sensor system related to smart sensing that enables danger prediction [8-10].

\subsection{Overview of Installation Test}

Figure 1 presents the test specimen shape and dimensions. This test piece is intended for exposed column bases of a low-rise steel frame. Plate $9 \mathrm{~mm}$ thick base is welded to a 100 $\times 100 \times 6 \mathrm{~mm}$ square steel pipe. It is fixed to the pedestal using 12 M27 anchor bolts. The joint between the base plate and the square tubular column is fixed by melting with a three-layer fillet weld.

Table 1. Load pattern characteristics.

\begin{tabular}{llll}
\hline Load & Maximum displacement $(\mathbf{m m})$ & Drift angle (rad) & Load direction \\
\hline Load 1 & 5 & $1 / 100$ & +- \\
Load 2 & 10 & $1 / 50$ & +- \\
Load 3 & 15 & $1 / 25$ & +- \\
\hline
\end{tabular}

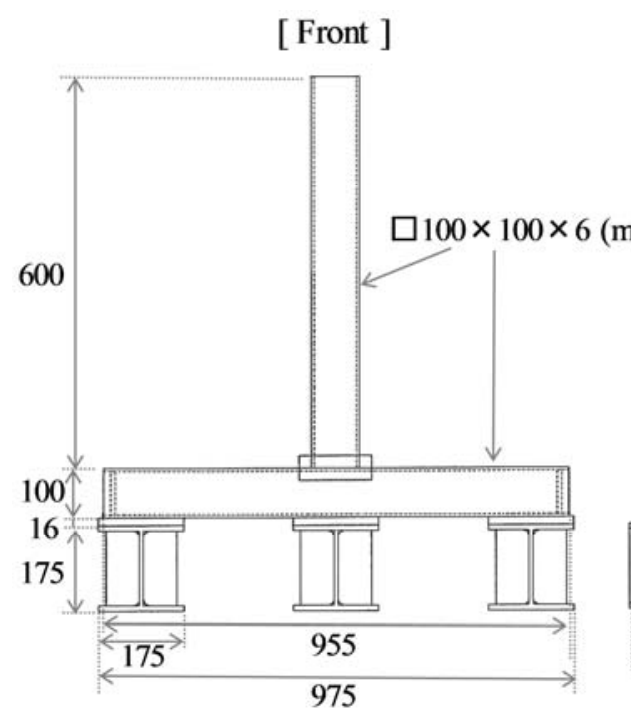

Figure 1. Test specimen layout.
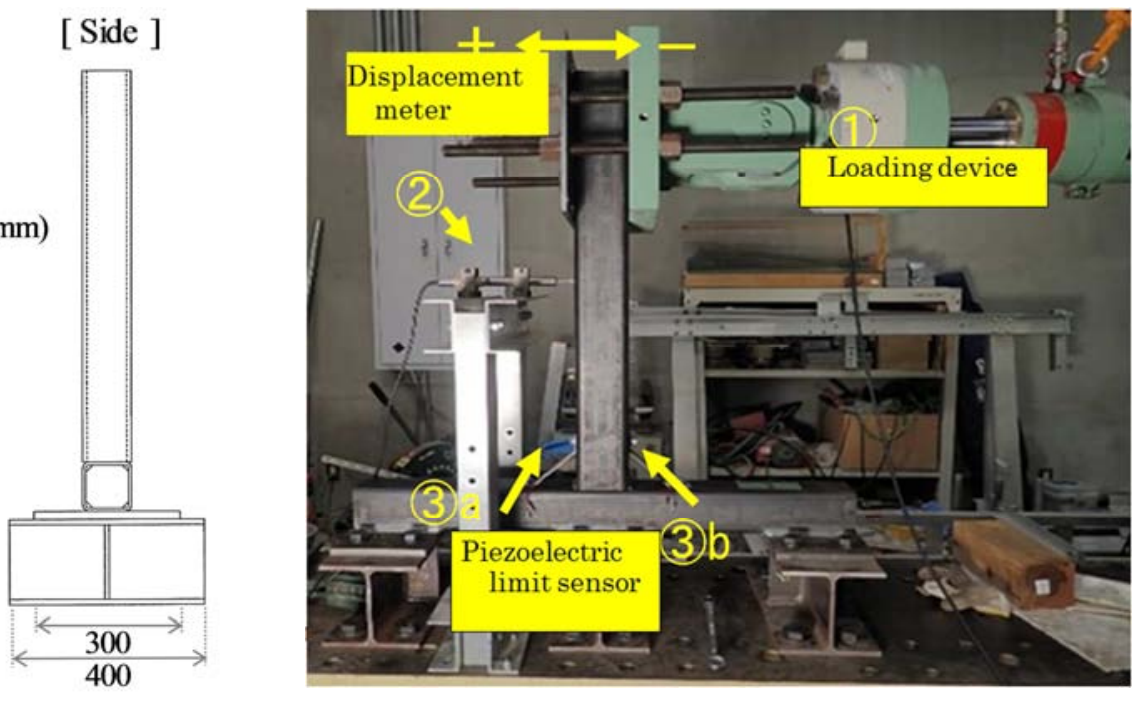

Figure 2. Load test devices 


\subsection{Test Method}

Figure 2 presents the measurement apparatus of (1) the loading device, (2) the displacement meter, and (3) the piezo electric joint sensor.

Figure 3 presents details of the piezoelectric joint sensor shape and dimensions. The piezoelectric joint sensor base plate is a $40 \times 190 \mathrm{~mm} \times 2 \mathrm{~mm}$ general rolled steel plate after drilling two $12.3 \mathrm{~mm}$ drill holes and an $8 \mathrm{~mm}$ hole for cable ducts, and after bending of both ends of about $40 \mathrm{~mm}$ at 135 deg. This angle is designed so that the piezoelectric joint sensor (Piezoelectric Film: DT-2-028 K/L [11]) can be mounted at a 45-degree angle to the weld surface when a square steel tubular column is welded in a T-shape. The sensor output has a structure in which maximum voltage of about $1 \mathrm{~V}$ is generated depending on the weld joint breakage state [12].

Figure 4 shows the anchor plate portion of the test specimen as fixed to the base using high tension bolts. A $500 \mathrm{kN}$ hydraulic jack was connected to the load section provided on the top of the test specimen. Then horizontal force was simulated during an earthquake. The horizontal force is based on the top displacement. The angle relation between the force and the inclination is presented in Table 1 [13]. Load 1 shown in the table is the limit of the safety standard in the Building Standards Law. Load 2 is the positive load corresponding to the deformation limit value during a strong earthquake. At applied force 3, deformation (displacement amount) of three times the applied force 1 is used, but the displacement value is equivalent to the numerical calculated value indicating complete failure of the test piece.
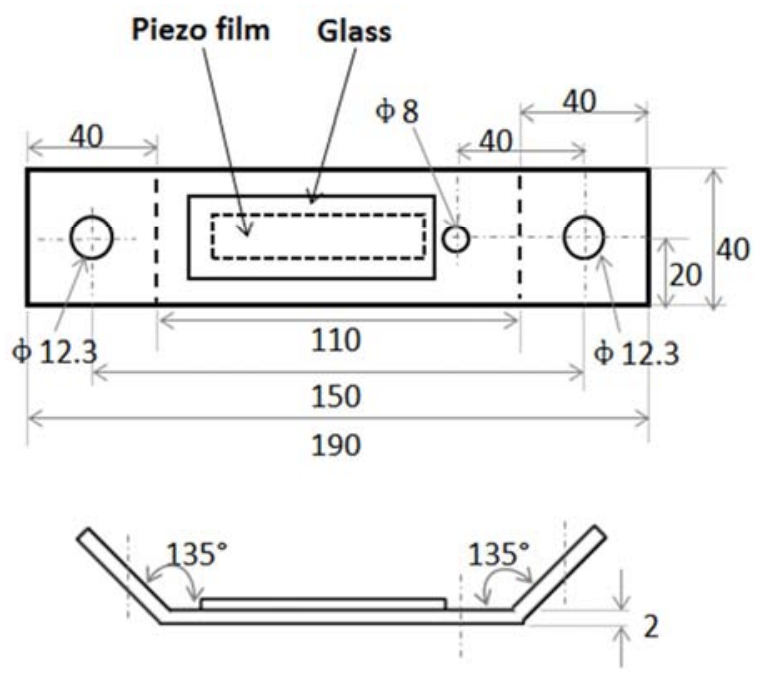

Figure 3. Piezoelectric limit sensor characteristics.

\section{Welding Joint Relation Between Displacement Measurement and Sensor Output}

\subsection{Relation Between Welding Force Applied to the Welded Joint and Piezoelectric Joint Sensor Output}

Figure 5 (a) portrays the + direction force and the output results for the piezoelectric joint sensor on the sensor $B$ side.
Measurement results indicate that the applied force became about $12 \mathrm{kN}$ when about $11 \mathrm{~min}$ and $45 \mathrm{~s}$ had passed. High output of about $+530 \mathrm{mV}$ and-70 $\mathrm{mV}$ was recorded from the sensor. Furthermore, measurement became difficult after output of about $+300 \mathrm{mV}$ and $-50 \mathrm{mV}$ from the sensor when the applied force was about $13 \mathrm{kN}$. The force was stopped after about 2 min to prevent danger. In all cases, the sensor output was shown clearly in front of the complete fracture region and near the limit region.

Figure 5 (b) presents a positive direction force and output results for the piezoelectric joint sensor on the sensor A installation side. Measurement results show that the applied force became about $12 \mathrm{kN}$ when about $11 \mathrm{~min}$ and $45 \mathrm{~s}$ had passed on the time axis. Output of about +52 $\mathrm{mV}$ and-120 $\mathrm{mV}$ from the sensor were recorded. Measurement became difficult after recording $+20 \mathrm{mV}$ output from the sensor when the applied force was about $13 \mathrm{kN}$. Furthermore, after recording $+20 \mathrm{mV}$ output from the sensor when the applied force was about $13 \mathrm{kN}$, it became difficult to measure. The sensor output on side A was confirmed immediately before the complete destruction region, but the sensor output on the B side was small: the value is about one-fifth of that of that A side. In addition, the output judgment near the limit area showed that the value was small and difficult to judge.

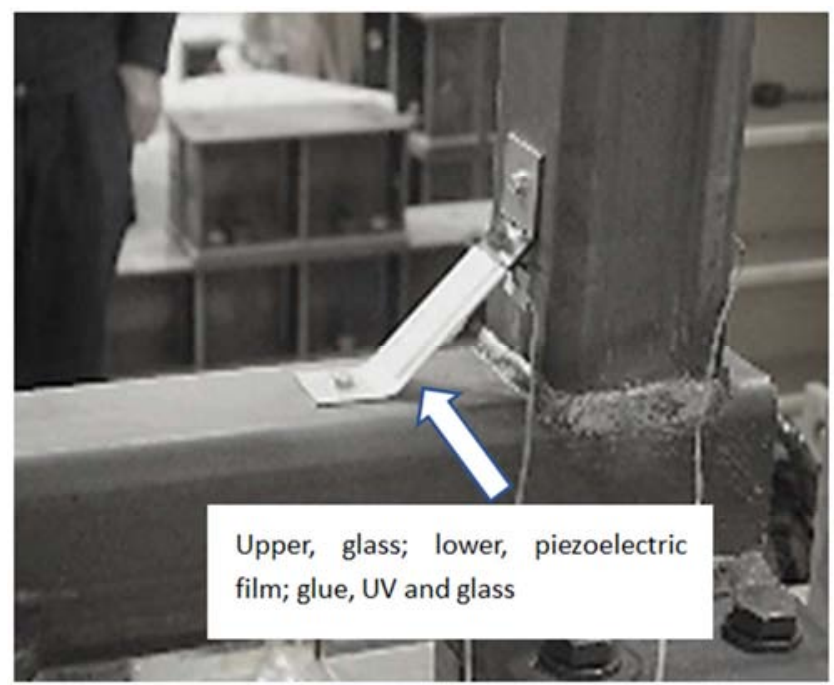

Figure 4. Setting of the piezoelectric limit sensor.

Figure 5 (c) presents the relation between the negative force and the output of the piezo limit sensor on the Sensor A installation side. About $34 \mathrm{~min}$ and $20 \mathrm{~s}$ after the sensor, when the applied force was in the negative direction and the applied force was about $10 \mathrm{kN}$, outputs of $+580 \mathrm{mV}$ and- $100 \mathrm{mV}$ were obtained from the sensor. Furthermore, after about $38 \mathrm{~min}$ and $30 \mathrm{~s}$, outputs of $+100 \mathrm{mV}$ and $-150 \mathrm{mV}$ were recorded at $13 \mathrm{kN}$ when the applied force was $13 \mathrm{kN}$. The sensor response was lost. After $2 \mathrm{~min}$ had elapsed, the applied force level.

On the minus side (pulling force) compared to the + side (pulling force), output was recognized earlier in the complete destruction area.

Figure 5 (d) presents the negative force and the output 
results for the piezo limit sensor on the Sensor B installation side. At approximately $34 \mathrm{~min}$ and $20 \mathrm{~s}$, the output from the sensor in the negative direction was about $100 \mathrm{mV}$ at about $10 \mathrm{kN}$. At about $38 \mathrm{~min}$ and $30 \mathrm{~s}$, the output was about $80 \mathrm{mV}$ at $13 \mathrm{kN}$ when the force was about $13 \mathrm{kN}$. Later, the loading was stopped for safety. Compared to the positive side compression, the negative side tensile force applied was $10 \mathrm{kN}$ for the first recording and $13 \mathrm{kN}$ for the second, similarly to that for Sensor a, with a low level output early in the complete destruction area. Similarly, force was stopped to prevent danger. The sensor A installation side output was confirmed immediately before complete destruction of the region, but the sensor $\mathrm{B}$ installation side output was small. The value is about one-fifth of that of that sensor A side. The output judgment near the limit area demonstrated that the value was small and difficult to judge.

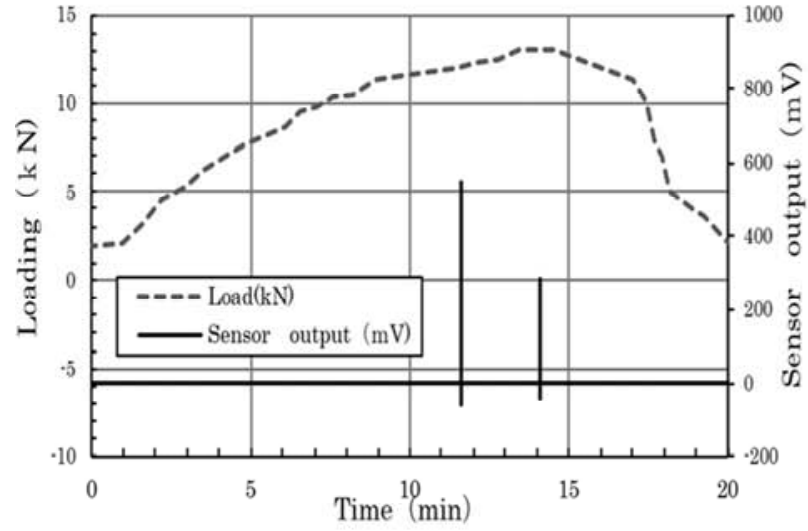

(a) Loading and piezoelectric limit sensor output $(+$ Direction load $\cdot$ sensor output $: B$ side )

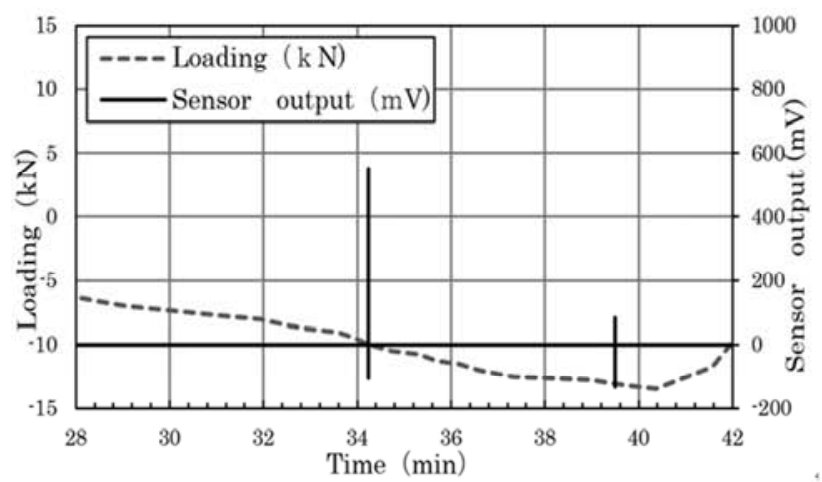

(c) Loading and piezoelectric limit sensor output. (- Direction load $\cdot$ sensor output : A side )

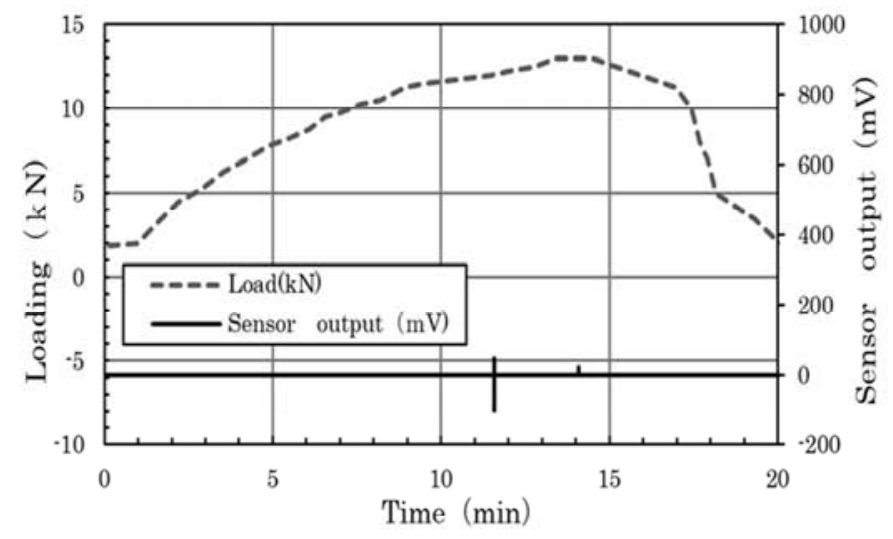

(b) Loading and piezoelectric limit sensor output (+ Direction load $\cdot$ sensor output : A side )

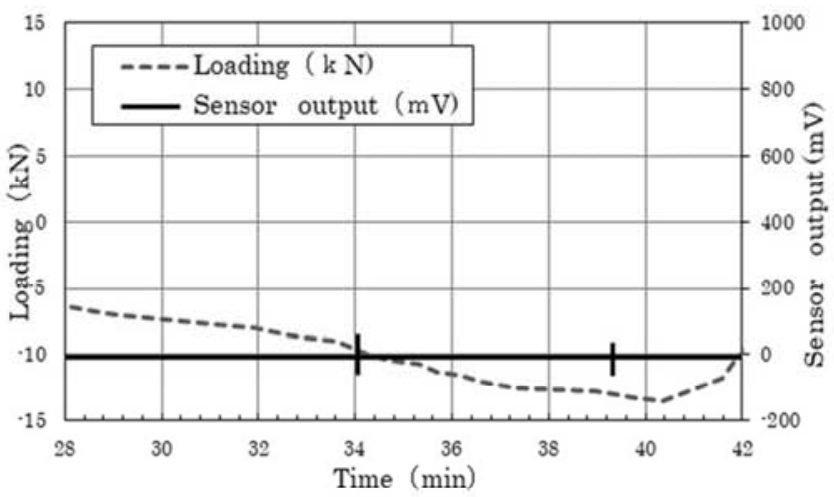

(d) Loding and piezoelectric limit sensor output.

(- Direction load $\cdot$ sensor output : B side )

Figure 5. Relation between piezoelectric limit sensor output and loading.

\subsection{Relation Between Sensor Joint Displacement and Sensor Output}

A maximum force of $15 \mathrm{kN}$ was applied in the + direction for about $20 \mathrm{~min}$. Then force was also applied to the-side under the same conditions. The relation between each displacement and the sensor output was measured.

Figure 6 (a) shows the displacement by the + direction force and the output result of the B side piezo electric joint sensor. When the displacement became about $8 \mathrm{~mm}$ after about 11 minutes and $45 \mathrm{~s}$, the sensor output showed high outputs of about $+530 \mathrm{mV}$ and-70 $\mathrm{mV}$. Furthermore, for displacement of about $10 \mathrm{~mm}$, the sensor output was about $+300 \mathrm{mV}$ and the output was about-50 $\mathrm{mV}$. The sensor response ceased after recording. Therefore, the loading was stopped after 2 min for safety. In each case, results show that the sensor output increased immediately before the complete destruction area and near the limit area.

Figure 6 (b) presents displacement attributable to the positive force and the output result of the piezo electric joint sensor. Based on the measurement results, the applied displacement $8 \mathrm{~mm}$ at about $11 \mathrm{~min}$ and $45 \mathrm{~s}$. From A side sensor outputs of about $+52 \mathrm{mV}$ and $-120 \mathrm{mV}$ were recorded.

In addition, at approximately displacement $10 \mathrm{~mm}$, the sensor output was about $+20 \mathrm{mV}$. Just stopped for safety after measuring from output the sensor. The sensor output can be confirmed immediately before the complete destruction area, but the sensor A value is about one-fifth less than the output of $\mathrm{B}$. In addition, the output judgment near the limit area was small and difficult to judge.

Figure 4 (c) shows the displacement applied in the-direction and the output result of the A side piezoelectric 
limit sensor. In addition, about 34 minutes and 20 seconds, when the displacement became $8 \mathrm{~mm}$ the sensor output was $+580 \mathrm{mV}$ and $-100 \mathrm{mV}$ were recoded. When the displacement become about-10mm after 4 minutes and $50 \mathrm{~s}$, sensor output showed level of $\pm 100 \mathrm{mV}$, After that, no output was recorded and the application was stopped after 2 minutes to prevent danger. Destruction progresses in about 2 times longer than the force in the + direction.

Figure 6 (d) presents the output result for sensor B side in the-direction displacement.

When the displacement became about-5 $\mathrm{mm}$ after about 34 minutes and $45 \mathrm{~s}$, the piezo electric sensor output showed low level outputs of about $+100 \mathrm{mV}$ and $-20 \mathrm{mV}$.

Furthermore, for displacement of about $10 \mathrm{~mm}$, the sensor output showed $+20 \mathrm{mV}$ and- $70 \mathrm{mV}$ were recoded.

\subsection{Load and Displacement Measurement Results Compared to Simulation Results at Welded Joints}

Using analysis software (FORUM8's subscription Ver.7 original specification), we analyzed the relation between force and displacement with spring coefficient added to a simplified welded structure model $[7,14,15]$.

Figure 7 portrays the test specimen. According to the analysis using a simplified model of the welded structure, the displacement in the critical area before fracture was $8 \mathrm{~mm}$. The displacement at complete fracture was $10 \mathrm{~mm}$.

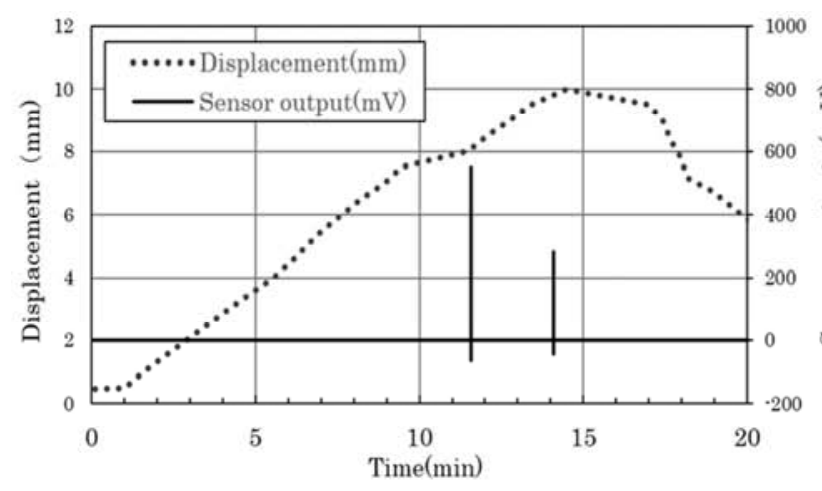

(a) Displacement and piezoelectric limit sensors output (+ Direction load $\cdot$ Sensor output :B side)

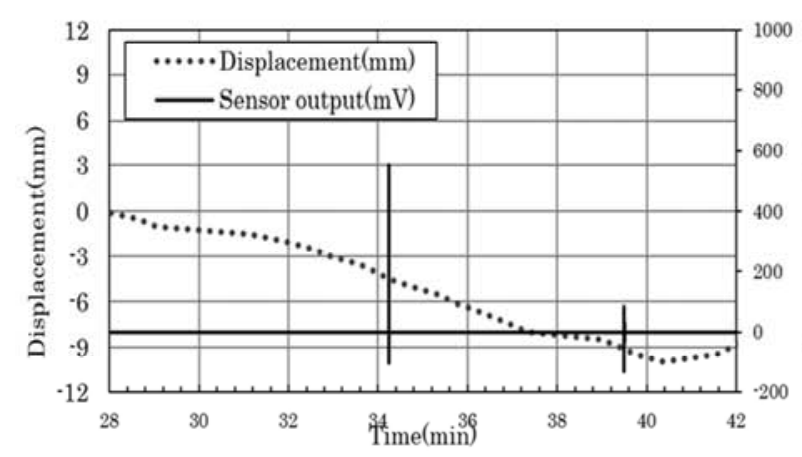

(c) Displacement and piezoelectric limit sensors output (-Direction load $\cdot$ Sensor output : A side )

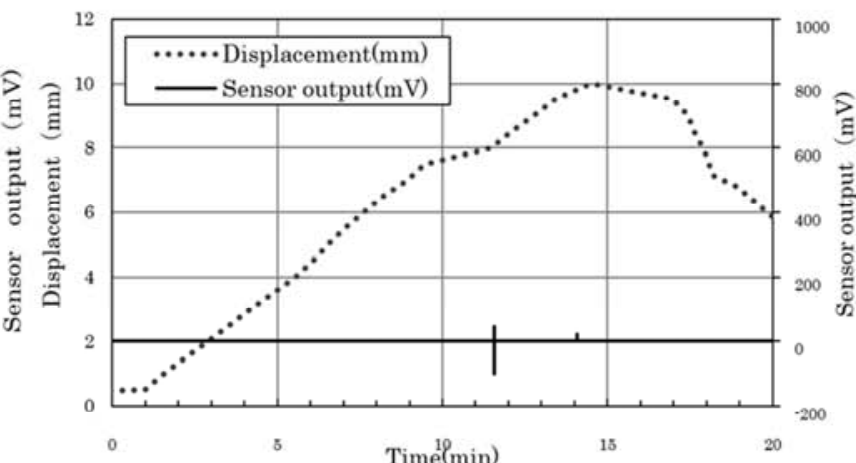

(b) Displacement and piezoelectric limit sensors output (+ Direction load $\cdot$ Sensor output :A side )

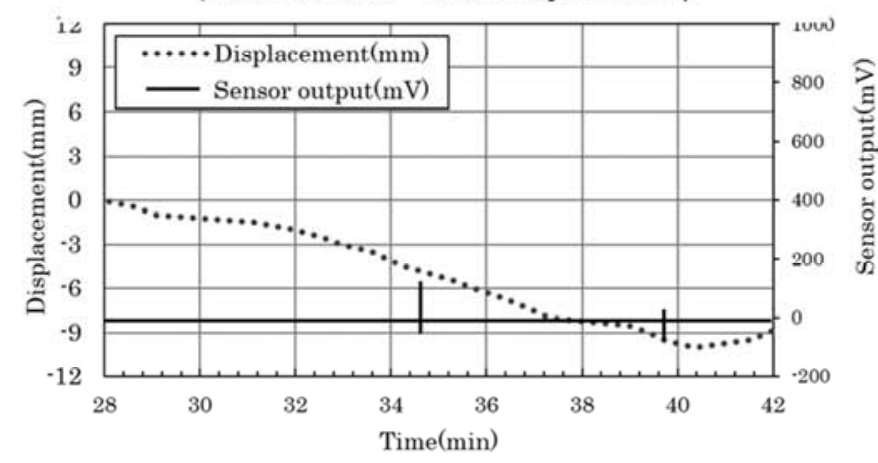

(d) Displacement and piezoelectric limit sensors output (-Direction load $\cdot$ Sensor output : B side )

Figure 6. Relation between piezoelectric limit sensor output and displacement.

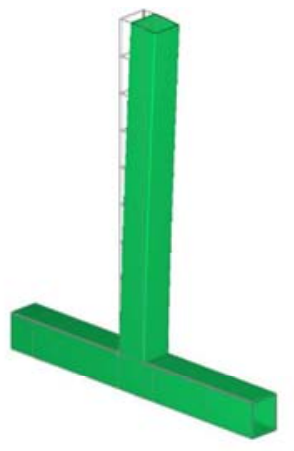

(a) Displacement of before complete destruction $(8 \mathrm{~mm})$

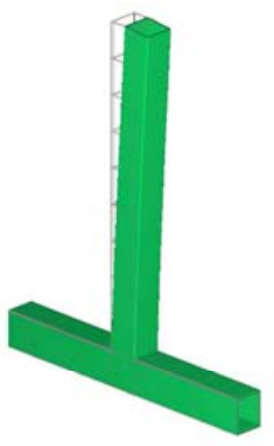

(b) Displacement of complete destruction $(10 \mathrm{~mm})$.

Figure 7. Three-dimensional finite element analysis of the load and displacement of the specimen layout. 
Simulation results show that the maximum displacements of $8 \mathrm{~mm}$ and $10 \mathrm{~mm}$ respectively occurred with $12 \mathrm{kN}$ and $15 \mathrm{kN}$. The output of this sensor also indicates a maximum value of about $0.6 \mathrm{~V}$. These results suggest that the piezo joint sensor reliability is high.

Figure 8 presents results of a comparison between the measured value and the analytically obtained value. The output result of the piezo limit sensor is displayed on the loop curve of the load and displacement relation obtained by numerical analysis. Values obtained through numerical analyses are shown as the broken line. The results of actual measurement are shown as the solid line. By comparison and verification, displacement proportional to the magnitude of the load was recognized. The piezo limit sensor output was also measured at the maximum displacement value, which was almost equal to the applied force. This result proves that it shows the same characteristics as the measurement results of the test specimen. Furthermore, regarding the relation between the applied force and displacement, results show large deformation on the tensile side, but small deformation on the compression side. Reliability was also demonstrated: similar results were obtained from numerical analysis of the welded structure.

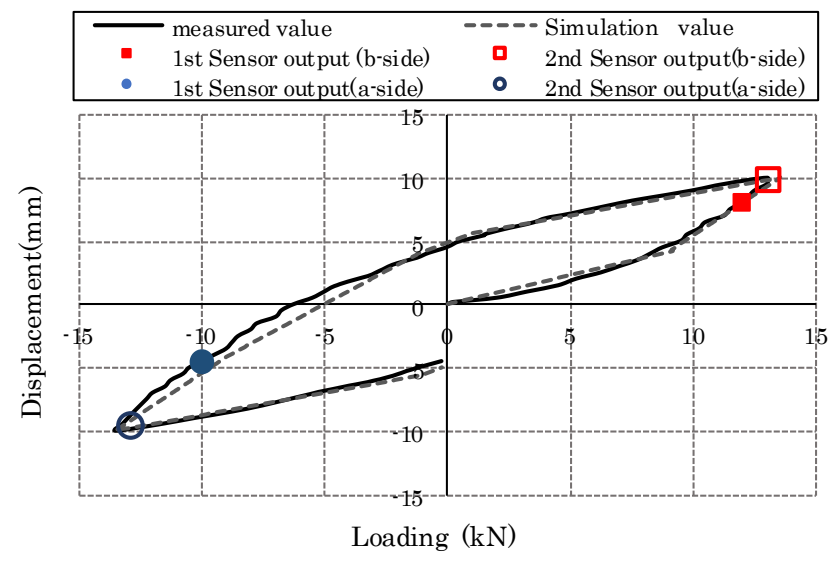

Figure 8. Relation between the load and displacement loop by simulation and sensor output point. As a feature, it has been found that the tensile side is deformed greatly; the compression side is reduced.

\section{Conclusion}

Considering results obtained for the applied force and sensor output 3, the figure and displacement and sensor output Figure 4 by the mounting test, based on the maximum output result of the sensor, the displacement was measured from 8 $\mathrm{mm}$ to $10 \mathrm{~mm}$, respectively, when the applied force was $12 \mathrm{kN}$ to $15 \mathrm{kN}$. The sensor effectiveness is shown also because the analysis result for displacement and the actual measured displacement are both $8-10 \mathrm{~mm}$ and because the piezo limit sensor measures the maximum output at the same point. Furthermore, regarding the relation between applied force and displacement, results showed that deformation on the tensile side increased and deformation on the compression side decreased rapidly. We obtained important reference values for future numerical analysis of welded structures. Moreover, we were able to obtain data that are expected to be helpful for structural design using welding. The piezoelectric joint sensor measurements used for this test had the characteristic of showing a critical value in the welded structure from the output results obtained under each condition, before the critical region where structural soundness is maintained. For this reason, a good possibility exists of conducting measurements for structural risk prediction. The possibility exists of long-term risk prediction measurement at joints of welded structures, where real-time monitoring of structural integrity is difficult using conventional methods. The wider use of this method is expected to contribute to construction and maintenance of a safe and secure society.

\section{Acknowledgements}

This research was partially supported by JSPS KAKENHI Grant No. 20H00290, for which we express our appreciation.

\section{References}

[1] Ministry of Land, Infrastructure and Transport, "Infrastructure maintenance information," (2020), https://www.mlit.go.jp/sogoseisaku/maintenance/02resear $\mathrm{ch} / 02$ 01 01.html

[2] H. Imai Narihara, I. Kawabata, M. Takayama, Y. Kimura, H. Aono and R. Kameda, Development of New Type of Steel Column Base Structural Experiment of Exposed-Type Column Base K. Imai, TAISEI Construction Technology Center, Technical Report, No. 39, 2006, pp. $1-6$.

[3] M. Mochizuki, M. Toyada, Y. Moriguchi, and T. Kubo, Residual Stress and Fatigue Strength in Welded Joints by Using Low-Temperature transformation weld material, Japan Welding Society, No. 72 (2003), pp. 242-243 (in Japanese).

[4] Steel Committee of Kinki Branch the Architectural Institute of Japan., Reconnaissance report on damage to steel building structures observed from the 1995 Hyogoken Nanbu Earthquake, (2005), pp. 22-108.

[5] H. Tanaka, A. Miyamoto, H. Emoto, A. Yabe, Long term application of a bus monitoring system to short ANDE medium span bridges and damage detection. Journal of Japan society of civil engineers provides access to rigorously refereed innovative research and practical papers across the fields of civil enginnrings. Vol. 70, No. 20 (2014), pp. 193-206.

[6] H. Tamai, Elasto Plastic Analysis Method for frame with exposed type column base considering influence of variable axial force, Journal of Structural and Construction Engineering (Transactions of AIJ) Vol. 68, No. 571 (2003), pp. 127-135.

[7] N. Shimoi, T. Nakatsu, C. Cuadra and K. Madokoro, Performance test of avalanche measurement fence using piezoelectric limit sensors, Japan Society of Mechanical Engineers, Vol. 84, No. 866 (2018), pp. 1-17. 
[8] G. Ouno, Study of technology for extending the life of existing structures, New urban society technology fusion research, The Second New Urban Social Technology Seminar (2003), pp. 11-23.

[9] J. Nakamura, Health monitoring of building structures, Society of Instrument and Control Engineers, Vol. 41, No. 11 (2002), pp. 819-824.

[10] K. Kumagaya, H. Nakamura and H. Kobayashi, Computer aided nondestructive evaluation method of welding residual stresses by removing reinforcement of weld, Journal of Mechanical Engineering Society (A) of Japan., Vol. 65 (1999), pp. 133-140.

[11] Tokyo Sensor Corporation, Piezoelectric cable, Piezo Film Technical Manual, R1 (2001), pp. 17-18.

[12] Y. Fujimoto and T. A. Setyant, Sheet Type Impact Force Sensor by the Use of Piezoelectric Film, Journal of
Mechanical Engineering Society (C) of Japan, Vol. 73, No. 725 (2007), pp. 184-191.

[13] K. Khannap, Miniature Pressure Sensor and Micro machined., Actuator Structure Based on Low-temperature Co-fired Ceramics and Piezoelectric Material, Materials Chemistry and Physics, No. 87 (2004), pp. 173-178.

[14] T. Yamanishi, T. Takamatsu, H. Tamai, T. Matsumura. and A. Tatuo, Models of restoring force characteristics and resistant mechanisms of exposed column-base under constant tensile axial-force, The Architectural Institute of Japan's Journal of Structural and Construction Engineering, Vol. 74, No. 637 (2009), pp. 561-567 (in Japanese).

[15] N. Shimoi, C. Cuadra and H. Madokoro, Development of simple analysis technology for steel structures, 13th Forum 8 design-festival, http://www.forum8.co.jp/fair/narda.htm\#nominate
(2019) 